\title{
RECOMENDAÇÕES, FRENTE A COVID-19, QUANTO AO USO DE VENTILADORES MECÂNICOS E CONDICIONADORES DE AR (SPLIT SYSTEM) EM AMBIENTES ESCOLARES
}

\author{
T. S. ANDRÉ \\ Universidade Federal da Paraíba \\ ORCID ID: https://orcid.org/0000-0003-1236-2909 \\ thiagoandreengmec@hotmail.com
}

Submetido 09/07/2020 - Aceito 23/11/2020

DOI: 10.15628/holos.2020.10711

\section{RESUMO}

A pandemia do COVID-19 anunciada pela Organização Mundial de Saúde (OMS) em março de 2020 trouxe uma reformulação e reanálise em muitas práticas existentes. Com a possibilidade de contaminação do novo coronavírus pelo ar faz-se necessária adaptações de muitos ambientes de vivência, entre eles a escola. Naturalmente, são locais que causam aglomeração de pessoas, e, devido ao distanciamento social, estão com suas atividades fins repensadas/readaptadas. Em aulas presenciais, um fator a ser considerado, além da proliferação do vírus, é o conforto térmico. No Brasil, são usados ventiladores mecânicos e sistemas de condicionamento de ar, tipo split system, com essa finalidade. Este artigo aponta caminhos a serem trilhados, quanto ao uso ou não de tais aparelhos, recomenda também protocolos de segurança a serem implementá-los ao tentar se promover um ambiente mais agradável, do ponto de vista térmico, objetivando a mitigação de possíveis proliferações aéreas do patógeno SARS-CoV-2 nas escolas, em um cenário com aulas e/ou trabalhos presenciais.

PALAVRAS-CHAVE: protocolo, renovação do ar, coronavirus, contaminação.

\section{RECOMMENDATIONS, AGAINST COVID-19, REGARDING THE USE OF MECHANICAL VENTILATORS AND AIR CONDITIONERS (SPLIT SYSTEM) IN SCHOOL ENVIRONMENTS}

\section{ABSTRACT}

The COVID-19 pandemic announced by the World Health Organization (WHO) in March 2020 brought with it a rethinking and re-analysis of many existing practices. The possibility of airborne contamination of the new coronavirus requires adaptations of many living environments, including school. Naturally, they are places that cause agglomeration of people, and, due to social distancing, are with their activities rethought/adapted. In face-to-face classes, one factor to be considered, besides the proliferation of the virus, is the thermal comfort. In Brazil, mechanical fans and air
\end{abstract}

conditioning systems are used, split system type, for this purpose. This article points out ways to be followed, regarding the use or not of such devices, also recommends safety protocols to be implemented when trying to promote a more pleasant environment, from the thermal point of view, aiming at mitigating possible aerial proliferation of the SARS-CoV-2 pathogen in schools, in a scenario with classes and/or face-to-face work.

KEYWORDS: protocol, air renewal, coronavirus, contamination.

HOLOS, Ano 36, v.5, e10711, 2020 


\section{INTRODUÇÃO}

Ventiladores mecânicos são máquinas que produzem circulação forçada de ar no ambiente, com fluxos de ar sob velocidade controlada, proporcionando da transferência de calor por convecção (CREDER, 2006). Os mais comuns, em ambientes escolares, são do tipo parede e teto.

Condicionadores de ar, tipo split system, proporcionam a redução de temperatura do ambiente com trocas de calor entre o fluido refrigerante (do aparelho) e o ar circulante no espaço a ser refrigerado. Estas máquinas não permitem, em sua maioria, a renovação do ar, isto é, a entrada/saída de ar externo (Creder, 2006; Miller, 2017).

O objetivo deste artigo é orientar/recomendar quanto ao uso adequado de máquinas que promovam, de alguma forma, a (re)circulação do ar nos espaços de trabalho, estudo e salas de aula, focando em medidas eficazes e sem custo para adoção.

\section{VENTILADORES MECÂNICOS}

A ABRAVA (2020), Associação Brasileira de Refrigeração, Ar Condicionado, Ventilação e Aquecimento, em um artigo intitulado "Perguntas Gerais a COVID-19 - Para setor Clientes e Usuários", apresenta como vigésima pergunta o enunciado: Em salas de aula dentro de escolas, é recomendado manter ventiladores de teto e laterais ligados? Nesse contexto, há salas de aula que possuem e outras que não possuem ar-condicionado com troca de ar, mas ambas possuem ventiladores de teto e laterais.

Como resposta à pergunta supra citada, a ABRAVA não recomenda o uso de ventiladores de teto ou parede (com função de trazer algum conforto térmico), pois promoveria uma mistura do ar contaminado por alguém portador do vírus, aumentado a possiblidade de proliferação do agente biológico.

Nessa mesma linha de pensamento, em um artigo intitulado "Air Conditioning May Be Spreading COVID", orienta o não uso de ventiladores, porque a movimentação do ar ocasionada pelo seu uso, podem transportar partículas virais suspensas no ar (Brenda Goodman, 2020).

Portanto, descartada está a hipótese do uso de ventiladores mecânicos, seja de teto, parede ou piso como substitutos dos condicionadores de ar.

Em casos de ambientes onde já existam, o fluxo de ar deve ser orientado na direção das portas ou janelas, ou seja, ventilador sem rotacionar, com posição fixa, preferencialmente, apontando para portas ou janelas abertas.

\section{CONDICIONADOR DE AR LIGADO}

A ASHARE (2020), American Society of Heating, Refrigerating and Air-Conditioning Engineers, uma das entidades mais respeitados do mundo na área técnica de ar condicionado, refrigeração e aquecimento, atuante há mais de 125 anos, em uma de suas declarações sobre o 
uso de sistemas de condicionador de ar, em meio a pandemia do COVID-19, fez a seguinte declaração:

\begin{abstract}
A ventilação e a filtragem fornecidas pelos sistemas de aquecimento, ventilação e ar condicionado podem reduzir a concentração de SARS-CoV-2 no ar e, portanto, o risco de transmissão pelo ar. Espaços não condicionados podem causar estresse térmico a pessoas que podem ser diretamente fatais e também podem diminuir a resistência à infecção. Em geral, desativar os sistemas de aquecimento, ventilação e ar condicionado não é uma medida recomendada para reduzir a transmissão do vírus.
\end{abstract}

Outras entidades, como ABRAVA, REHVA (2020), Federation of European Heating, Ventilation and Air-conditioning Associations, também possibilitam o uso ativo dos sistemas de ar condicionado, com as precauções devidas.

Outras entidades, como ABRAVA6, REHVA (Federation of European Heating, Ventilation and Air-conditioning Associations) também possibilitam o uso ativo dos sistemas de arcondicionado, com as precauções devidas (ASHRAE, 2020).

Baseado no protocolo de uso de equipamentos e sistemas de ar-condicionado pós quarentena, a ABRAVA (2020), recomenda as seguintes ações, caso o condicionador de ar seja ligado:

- Manter os condicionadores de ar limpos e higienizados, primordialmente sifões, bandejas, ventiladores e serpentinas, de acordo com orientações do fabricante e PMOC (plano de manutenção, operação e controle), construído conforme a Lei no 13.589 .

- Limpar os filtros de ar com periodicidade indicada pelos fabricantes e trocá-los ao fim da sua vida útil.

- Usar o condicionador de ar, preferencialmente, no modo ventilação, com portas e janelas parcialmente ou totalmente abertas.

- Em último caso, quando da necessidade devido ao desconforto térmico, usar no modo resfriar, com baixa velocidade de ventilação, com portas e janelas parcialmente abertas.

\title{
4 CONDICIONADOR DE AR DESLIGADO
}

Há crescente discussão sobre a possibilidade da transmissão do patógeno SARS-CoV-2 por vias aéreas (Morawskaa \& CAO, 2020). Além deste, (LU et al, 2020) demonstrou a possibilidade de contaminação causada pelas correntes de ar provenientes do aparelho de ar-condicionado, isto em um ambiente sem janelas. Portanto, não ligar o aparelho é a possibilidade mais conservadora.

O primeiro protocolo de biossegurança do Ministério da Educação (2020), em tempos de pandemia, trata do retorno presencial em tempos nas instituições federais de ensino, orienta em suas diretrizes, a manutenção dos ambientes escolares, salas, refeitórios, auditórios entre outros, ventilados (portas e janelas abertas). 
Caso o condicionador de ar não seja ligado, e o ambiente não possua sistema de exaustão ou ventilação mecânica diluidora, recomenda-se:

- Abertura de portas e janelas para promoção da renovação do ar e favorecimento da ventilação cruzada (direcionamento da entrada e saída do ar, conforme a direção do vento).

De acordo com CREDER (2006), janelas ou portas em duas paredes, como é o caso das salas e ambientes de boa parte das escolas, proporcionam 1,5 trocas de ar por hora nos ambientes, ou seja, renovação de todo o ar contido no meio por meio da abertura das portas e janelas existentes.

A OMS (2020) em seu artigo intitulado "Getting your workplace ready for COVID-19" recomenda que portas e janelas, sempre que possível, sejam mantidas abertas para garantir uma boa ventilação.

Em carta aberta enviada a OMS, intitulada "It is Time to Address Airborne Transmission of COVID-19", assinada por 239 cientistas de todo mundo, Morawskaa \& Milton (2020) autores principais, recomendam a ventilação eficiente e eficaz, com tomada de ar externo limpo e diminuição da recirculação proporcionada por aparelhos de condicionamento de ar. Estas ações, de acordo com os pesquisadores, podem ser realizadas pela simples abertura de portas e janelas.

Um documento publicado pela REHVA (2020), nomeado "COVID-19 Guidence", orienta que em locais onde há ventilação artificial, como é o caso de boa parte das escolas, janelas sejam mantidas abertas para promoção da renovação do ar interior, apesar do desconforto térmico a ser causado.

\section{OUTRAS POSSIBILIDADES}

No artigo "Additional guidance for use of fan coils and avoiding recirculation", a REHVA (2020) ainda recomenda que unidades de condicionamento de ar sejam mantidas, preferencialmente, desligadas ou, quando não for possível, que funcionem de modo contínuo, com baixa velocidade, evitando a sedimentação do vírus no equipamento.

A ANVISA (2003), Agência Nacional de Vigilância Sanitária, indica como taxa de renovação de ar, uma vazão de $27 \mathrm{~m}^{3} /$ hora/pessoa. Uma porta aberta na parede externa, com mais de $90 \mathrm{~cm}$ e menos de $180 \mathrm{~cm}$, promove a entrada de $2000 \mathrm{~m}^{3} /$ hora de ar no ambiente segundo Creder (2006).

Em outros termos, uma porta aberta durante 30 minutos, promoverá a renovação de ar para um ambiente com aproximadamente 35 pessoas. A desvantagem está no aumento da carga térmica local, com aumento da temperatura durante a abertura.

O artigo chinês "COVID-19 Outbreak Associated with Air Conditioning in Restaurant" (Lu et al, 2020) apresenta, em uma de suas conclusões, que melhorar a ventilação e aumentar o distanciamento entre as pessoas (maior que um metro), diminui o risco de infecção pelo vírus, considerando pessoas assintomáticas e fora do fluxo do ar-condicionado. Não há, isto posto, uma orientação para desligamento do aparelho de ar-condicionado. 
Portanto, a depender da situação climática na cidade, por exemplo, em dias muito quentes, pode-se adotar a seguinte estratégia: condicionador de ar (split-system) ligado por meia hora, modo resfriar, baixa velocidade, com portas e janelas parcialmente abertas; condicionador de ar ligado por meia hora, modo ventilação, baixa velocidade com a porta e janelas parcialmente abertas.

De outra forma, uma aula ou hora com o condicionador de ar ligado no modo resfriar, baixa velocidade, ambiente com portas e janela parcialmente abertas. Uma aula ou hora com o condicionador de ar ligado no modo ventilação, com as portas e janelas totalmente abertas.

Ciclos de funcionamento entre os turnos, ou nos horários mais quentes do dia, podem ser adotados.

\section{PROTEÇÃO AOS PROFISSIONAIS DE PROTEÇÃO}

Por fim, aos profissionais responsáveis pela limpeza/higienização e manutenção dos condicionadores de ar, cabe o dever de atentar-se ao uso dos seguintes equipamentos de proteção individual (EPI) e seguir as recomendações listadas abaixo (ABRAVA, 2020):

- Máscara do tipo face shield acrescida de máscara N-95 ou caseiras, óculos de proteção, luvas de borracha, calça comprida, camisa manga longa e sapato fechado.

- Descartar os filtros substituídos em sacos hermeticamente fechados.

- Não retirar o filtro novo, da embalagem, antes da devida aplicação no equipamento.

- Acessar os locais de manutenção somente de pessoas autorizadas.

- Recolher equipamentos, ferramentas e materiais usados na manutenção/higienização.

- Deixar o local onde foi realizado a manutenção limpo, além de recolher e/ou descartar restos e sobras de materiais.

\section{CONCLUSÃO}

Importante ressaltar que essas medidas representam uma parcela dentre outras que serão tomadas quando de um retorno presencial. Some-se a isto o uso de máscaras, o distanciamento mínimo de 1,5 metros entre estações de trabalho ou carteiras e a higienização das mãos como ações mitigadoras da proliferação do coronavírus em todos os ambientes.

Primordialmente, não se deve ligar sistemas de ar-condicionado ou ventiladores mecânicos, deve-se, pois, adotar um sistema de ventilação natural, com abertura de portas e janelas. Mais vale a vida que o conforto térmico, em tempos de tantas incertezas e informações cruzadas, por vezes, quanto ao modo de enfrentar o COVID-19.

Caso não seja possível o atendimento a esta orientação, proceder conforme as indicações mencionadas no corpo do artigo. 
Outrossim, as legislações locais, protocolos de órgãos do governo, recomendações de entidades de classe (engenharia e saúde), entre outas entidades representativas, devem ser observadas quando da implementação de alguma medida, de modo a evitar o conflito de interesse.

Estas orientações podem ser complementadas/retificadas à medida que novas informações/orientações dos especialistas/autoridades de saúde ou governamentais forem divulgadas.

\section{REFERÊNCIAS}

ABRAVA. Perguntas Gerais a COVID-19 - Para setor Clientes e Usuários. Disponível em: $<$ https://abrava.com.br/normalizacoes/canal-abrava-covid-19/perguntas-gerais-covid-19para-setor-cliente-usuarios/>. Acesso em 06 de junho de 2020.

ABRAVA. Protocolos para suo dos equipamentos e sistemas de ar condicionado no pósquarentena. Disponível em: <https://abrava.com.br/abrava-protocolos-para-uso-dosequipamentos-e-sistemas-de-ar-condicionado-no-pos-quarentena-pos-quarentena/>. Acesso em 06 de junho de 2020.

AGÊNCIA NACIONAL DE VIGILÂNCIA SANITÁRIA. Resolução no 9, de 16 de janeiro de 2003.

AMERICAN SOCIETY OF HEATING, REFRIGERATING AND AIR-CONDITIONING ENGINEERS. Declarações.

Disponível

em: $<$

https://www.ashrae.org/file\%20library/technical\%20resources/covid19/declaraci\%C3\%B3ne s.pdf>. Acesso em 08 de julho de 2020.

AMERICAN SOCIETY OF HEATING, REFRIGERATING AND AIR-CONDITIONING ENGINEERS. ASHRAE Issues Statements on Relationship Between COVID-19 and HVAC in Buildings. Atlanta: 20 de abril de 2020. Disponível em:< https://www.ashrae.org/about/news/2020/ashrae-issuesstatements-on-relationship-between-covid-19-and-hvac-in-buildings $>$. Acesso em 08 de julho de 2020.

BRASIL. Lei no 13.589, de 4 de janeiro de 2018. Dispõe sobre a manutenção de instalações e equipamentos de sistemas de climatização de ambientes. Disponível em: < http://www.planalto.gov.br/ccivil_03/_ato2015-2018/2018/lei/l13589.htm>. Acesso em 8 de julho de 2020.

Brenda Goodman, MA. Air Conditioning May Be Spreading COVID. Webmd Health News 2020: jul. Disponível em: <https://www.webmd.com/lung/news/20200708/air-conditioning-may-bespreading-covid>. Acesso em 10 de julho de 2020.

CREDER, Hélio. Instalações de Ar Condicionado. 6a edição. Rio de Janeiro: LTC, 2006.

FEDERATION OF EUROPEAN HEATING, VENTILATION AND AIR-CONDITIONING ASSOCIATIONS. COVID-19 Guidence. Bruxelas, 03 de abril de 2020. Disponível em: < https://www.rehva.eu/activities/covid-19-guidance>. Acesso em 08 de julho de 2020. 
FEDERATION OF EUROPEAN HEATING, VENTILATION AND AIR-CONDITIONING ASSOCIATIONS. Additional guidance for use of fan coils and avoiding recirculation. Bruxelas, 03 de abril de 2020. Disponível em: < https://www.rehva.eu/fileadmin/user_upload/REHVA_COVID19_specific_guidance_document_-_Use_of_fan_coils_and_avoiding_recirculation_.pdf $>$. Acesso em 08 de julho de 2020.

Lu, J., Gu, J., Li, K., Xu, C., Su, W., Lai, Z., Zhou, D., You, C., Bin, X., Yang, Z. (2020). COVID-19 Outbreak Associated with Air Conditioning in Restaurant, Guangzhou, China, 2020. Emerging Infectious Diseases, 26(7), 1628-1631. https://dx.doi.org/10.3201/eid2607.200764. Acesso em 09 de julho de 2020.

Miller R, Miller MA. Ar Condicionado e Refrigeração. 2 ed. Rio de Janeiro: LTC, 2017.

MINISTÉRIO DA EDUCAÇÃO. Protocolo de biossegurança para retorno das atividades nas Instituições Federais de Ensino. Brasília: julho, 2020. Disponível em:< https://www.gov.br/mec/pt-br/centrais-deconteudo/campanhas1/coronavirus/CARTILHAPROTOCOLODEBIOSSEGURANAR101.pdf/view >. Acesso em 9 de julho de 2020.

MORAWSKA, Lidia; MILTON, Donald K. It is Time to Address Airborne Transmission of COVID-19, Clinical Infectious Diseases, ciaa939, https://doi.org/10.1093/cid/ciaa939. Disponível em:< https://academic.oup.com/cid/article/doi/10.1093/cid/ciaa939/5867798>. Acesso em 8 de julho de 2020.

MORAWSKAA, Lidia; CAO, Junji. Airborne transmission of SARS-CoV-2: The world should face the reality. Elsevier Public Health Emergency Collection. Publicado online em 2020, 10 de abril. Doi: $\quad 10.1016$ / j.envint.2020.105730. Disponível em: < https://www.ncbi.nIm.nih.gov/pmc/articles/PMC7151430/>. Acesso em 08 de julho de 2020.

World Health Organization. Getting your workplace ready for COVID-19. Genebra, 19 de março de 2020. Disponível em: < https://www.who.int/docs/default-source/coronaviruse/advicefor-workplace-clean-19-03-2020.pdf?sfvrsn=bd671114_6\&download=true $>$. Acesso em 08 de julho de 2020.

\section{COMO CITAR ESTE ARTIGO:}

André, T. da S. (2020). Recomendações, frente a covid-19, quanto ao uso de ventiladores mecânicos e condicionadores de ar (split system) em ambientes escolares. Holos. 36(5), 1-8.

\section{SOBRE OS AUTORES}

\section{T. da S. André}

Graduação em Engenharia Mecânica e Mestre em Engenharia Mecânica. Doutorando do Programa de PósGraduação em Engenharia Mecânica. E-mail: thiagoandreengmec@hotmail.com ORCID ID: http://orcid.org/0000-0003-1236-2909 
Pareceristas Ad Hoc: ALVARO OCHOA E ADRIANA APARECIDA DE SOUZA

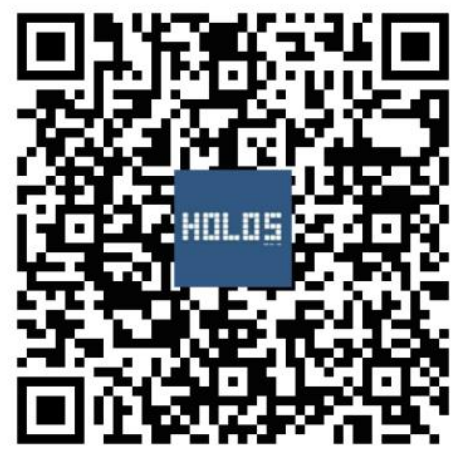

